\section{Accidental Intrarectal \\ Administration of Alcohol \\ Enema Induces Proctocolitis and Fecal Incontinence}

At 2 hours before an elective colonoscopy indicated for abdominal pain in a 67-yearold woman, the patient's sister wrongly administered $250 \mathrm{~cm}^{3}$ of "cleansing enema" containing ethyl alcohol $96 \%$. The patient experienced a perineal and anorectal burning pain, severe abdominal pain, profuse and involuntary diarrhea, tenesmus, rectal bleeding, and the emission of numerous white plaques mixed with and all over the liquid feces. We diagnosed a severe colonic mucosal sloughing with a possible secondary perforation. A conservative treatment was prescribed of intravenous fluids and electrolytes, and intravenous cefotaxime, metronidazole, and analgesics. We had no evidence-based reasons to prescribe her steroids, so we treated our patient's acute proctocolitis as an ischemic colitis.

After 24 hours, we performed a careful flexible colonoscopy (Figures $\mathbf{1}$ and $\mathbf{2}$ ). For the next 7 days, the patient improved with less abdominal pain, lack of peritonism signs and no bleeding, the diarrhea stopped and she was able to eat and move almost normally. She continued outpatient treatment comprising of oral antibiotics for a further 7 days. Fecal incontinence was the last symptom to disappear, by the $3 \mathrm{rd}$ week.

A month later, when she was symptomless, we performed a total colonoscopy and observed only a mild patchy erythema on rectal and sigmoid mucosa, no white plaques, no stenosis, and many small noncomplicated colon diverticula mainly distributed in the sigmoid colon. At the last visit, 1 year later, the patient was completely asymptomatic and there were no inflammatory features at colonoscopy.

Acute colitis has been described after rectal instillation of detergent or chemical substances $[1,2]$. This is the fourth case reported in medical literature referenced in Medline of alcohol-induced proctitis involving ethyl alcohol [3-5]. Our case is the first to describe fecal incontinence that occurred as the result of an accidental ethyl alcohol enema administered prior to an elective colonoscopy.

It is possible that these accidental instillations occur more frequently in clinical practice but to a less severe degree, probably because patients notice perineal burning initially and quickly remove the

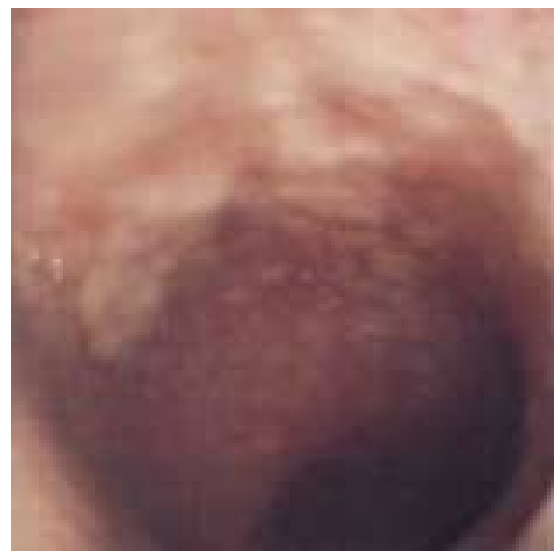

Figure 1 Colonoscopy revealed confluent white plaques adherent to underlying distal rectal mucosa and covering partially the anal canal and perianal epidermis. The fecal incontinence was extremely severe, and occurring when the patient was upright

cleansing enema. We think endoscopic follow-up should not take place until at least 3 weeks after alcohol instillation, as a perforation could occur if a colonoscopy is done with normal insufflation. Our case shows the endoscopic features and clinical manifestations of alcohol-induced functional and structural damage to the anus, rectum and colon, with complete resolution after conservative treatment.

M. Rodriguez-Tellez ${ }^{1}, J$. M. Herrerias $J r$., F. Argüelles, M. J. Gonzalez-Mariscal, F. J. Pellicer ${ }^{l}$, J. M. Herrerias

${ }^{1}$ Endoscopy Unit, Division of Digestive Diseases, Virgen Macarena University Hospital of Seville, Spain

\section{References}

${ }^{1}$ Jonas G, Mahoney A, Murray J, Gertler S. Chemical colitis due to endoscope cleaning solutions: a minic of pseudomembranous colitis. Gastroenterology 1988; 95: 1403

${ }^{2}$ Davila AD, Willenbucher RF. Other diseases of the colon and rectum: melanosis coli, cathartic colon, and soap or chemical colitis. In: Feldman M, Sleisenger MH, Scharschmitt B (eds). Sleisenger and Fordtran's gastrointestinal and liver disease. Philadelpha: Saunders, 1998: 1992-1995

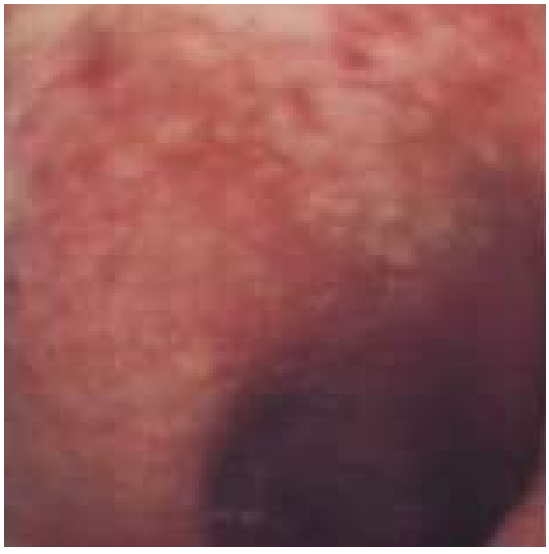

Figure 2 Proximal rectal mucosa showed a severe erythema and mucosal denudation, probably as a result of the rectal bleeding and the detachment of fibrin white plaques overlying a few hours before

${ }^{3}$ Herrerias JM, Muniain MA, Sanchez S, Garrido M. Alcohol-induced colitis. Endoscopy 1983; 15: 121-122

${ }^{4}$ Bhalotra R. Alcohol-induced proctitis in a human. J Clin Gastroenterol 1988; 10: 592

${ }^{5}$ Triantafillidis JK, Vekini J, Nicolakis D, Emmanouilides A. Ethanol-induced proctitis: another kind of chemical proctitis. Am J Gastroenterol 1994; 89: $1270-1271$

Corresponding Author

Dr. M. Rodriguez-Tellez

C/Rafael Belmonte Garcia

4 Puerta 8

Sevilla 41010

Spain

Fax: +34-955-008805

E-mail: mrodrigueztellez@ medynet.com 